\title{
A STUDY ON AETIOLOGY AND OUTCOME OF SHOCK IN CHILDREN
}

\author{
Deepa Kunju Krishnan¹, Jayaprakash Kochupurackal Parameswaran²
}

${ }_{1}^{1}$ Assistant Professor, Department of Paediatrics, Institute of Child Health, Government Medical College, Kottayam, Kerala, India. ${ }^{2}$ Assistant Professor, Department of Paediatrics, Institute of Child Health, Government Medical College, Kottayam, Kerala, India.

\section{BACKGROUND}

ABSTRACT

Shock is one of the most common paediatric emergencies with significant mortality if not recognized and treated early. There are five major categories of shock, of which septic shock is increasing in incidence, the world over. This study aims to describe the aetiology and outcome of shock in children.

\section{MATERIALS AND METHODS}

This is a retrospective descriptive study conducted in a tertiary care hospital. 70 children who were admitted over a 2-year period with a diagnosis of shock were included in the study. The clinical details were collected from the case records and entered in a proforma.

\section{RESULTS}

$50 \%$ of children with shock were in the 1-5 years age group. The commonest type of shock was septic shock (68.5\%), then hypovolemic shock (21.5\%), cardiogenic shock (7.2\%) and distributive shock (2.8\%). The overall mortality rate was $28.5 \%$. However, when cardiogenic shock was considered alone, the mortality was $60 \%$ and in septic shock, it was $35 \%$.

\section{CONCLUSION}

Septic shock is the commonest cause of shock in children followed by hypovolemic shock. Septic shock and cardiogenic shock are associated with high mortality.

\section{KEY WORDS}

Aetiology, Shock, Children, Outcome

HOW TO CITE THIS ARTICLE: Krishnan DK, Parameswaran JK. A study on aetiology and outcome of shock in children. J. Evolution Med. Dent. Sci. 2019;8(10):671-673, DOI: 10.14260/jemds/2019/149

\section{BACKGROUND}

Shock is an acute syndrome characterized by the body's inability to deliver adequate oxygen to meet the metabolic demands of vital organs and tissues. ${ }^{1}$ Shock occurs in approximately $2 \%$ of all hospitalized patients. ${ }^{2}$ In developing countries hypovolemic shock especially that associated with acute diarrheal diseases is one of the leading causes of shock. However, the incidence of septic shock is increasing the world over. This is due to the fact that more patients are surviving with diseases which were fatal previously and also because of an increase in invasive procedures. Shock is one of the most common paediatric emergencies with significant mortality if not recognized and treated early. Septic shock, when in decompensated state is associated with a mortality of up to $50 \%$ in some studies. ${ }^{3}$ There are very few studies on paediatric shock from India. Some of these studies show an increasing incidence of septic shock in India. ${ }^{4}$

This study aims to find out the type, aetiology and outcome of shock in children in a tertiary care hospital.

'Financial or Other Competing Interest': None.

Submission 09-01-2019, Peer Review 19-02-2019,

Acceptance 25-02-2019, Published 11-03-2019.

Corresponding Author:

Deepa Kunju. Krishnan,

Assistant Professor,

Department of Paediatrics,

Institute of Child Health,

Government Medical College,

Kottayam-686030,

Kerala, India.

E-mail: deepapullayil@yahoo.in

DOI: $10.14260 /$ jemds $/ 2019 / 149$

\section{(c) (i) () $\Theta$}

\section{MATERIALS AND METHODS}

This is a retrospective descriptive study conducted in the Department of Paediatrics, Government medical college, Kottayam. All children from 1 month to 12 years of age admitted with a diagnosis of shock during the time period June 2015 to June 2017 were included in the study.

Shock was defined as a clinical state in which the recorded blood pressure was below the $5^{\text {th }}$ centile for age or 2 standard deviations below the mean for age $^{5}$ and /or a state in which at least three of the following criteria for decreased perfusion were identified. ${ }^{6}$

1. Weak peripheral pulses

2. Mottled/cool extremities with a capillary refill of more than 3 seconds.

3. Tachycardia-(heart rate $>180 /$ beats/minute for infants and $>160$ beats /minute for children), or bradycardia (heart rate $<60$ beats/ minute)

4. Urine output $<0.5 \mathrm{ml} / \mathrm{kg} / \mathrm{hr}$.

Shock was further classified as compensated shock, in which the blood pressure is maintained and a stage of decompensated shock, with hypotension. Shock was also categorized into five major types, hypovolemic shock, cardiogenic shock, obstructive shock, distributive shock and septic shock.

Hypovolemic shock was diagnosed when there was a history of fluid loss like vomiting, diarrhoea, loss of blood etc. and physical findings. Cardiogenic shock was identified when there were findings pointing towards a primary myocardial involvement. Distributive (anaphylactic) shock, was diagnosed when there was sudden cardiovascular collapse following exposure to an inciting agent. Septic shock was diagnosed when sepsis plus cardiovascular organ dysfunction was present. 
Data was collected from the medical records of patients and entered in a proforma. Data was analysed statistically, and variables were expressed as percentage.

\section{RESULTS}

A total of seventy children were diagnosed as having shock. Of their 21 patients (30\%) were in the age group of 1 month to 1 year. 35 patients $(50 \%)$ were in the $1-5$ years age group and 14 patients (20\%) were in the 5-12 years age group. 44 patients in the study were male (62.8\%) and 26 were female (37.2\%).

$50 \%$ of the cases were in compensated stage of shock. Considering the different functional categories of shock, 48 patients were diagnosed with septic shock, 15 patients with hypovolemic shock. There were 2 patients with cardiogenic shock and 2 patients with anaphylactic shock.

\begin{tabular}{|c|c|}
\hline Categories of Shock & Number of Patients \\
\hline Septic & $48(68.5 \%)$ \\
\hline Hypovolemic & $15(21.5 \%)$ \\
\hline Cardiogenic & $5(7.2 \%)$ \\
\hline Distributive & $2(2.8 \%)$ \\
\hline
\end{tabular}

Among the 48 patients with septic shock pneumonia was the commonest infection seen in 26 patients 954.2\%). Dengue shock syndrome was the diagnosis in 12 patients (29.10\%). Other infections associated with septic shock were meningitis 3 patients $(6.2 \%)$, urinary tract infections 2 patients $(4.16 \%)$ intrabdominal infections 2 patients $(4.16 \%)$ and cellulitis in 1 patient (2.1\%).

Blood culture was positive in 12 patients (20\%). Klebsiella and staphylococcus aureus were seen in 3 patients each.

MRSA and coagulase negative staphylococcus aureus were found in 2 patients each. E Coli was cultured from 1 patient and pseudomonas from one patient.

Most common cause of hypovolemic shock was acute diarrhoeal disease which accounted for $90 \%$ of hypovolemic shock.

Of the 5 cases of cardiogenic shock, congenital heart disease was the most common underlying aetiology, accounting for 2 cases 1 patient had dilated cardio myopathy and 1 had myocarditis. Wasp sting was the cause of two cases of distributive shock.

Out of the 70 patients is the study 20 expired (28.5\%). The highest mortality of $60 \%$ was seen in cardiogenic shock, where 3 out of 5 patients died. In septic shock, 35.4\% (17 patients) expired. $75 \%$ of the patients with septic shock, who died presented in a late decompensated stage and about $50 \%$ of them had co-morbidities like global developmental delay and cerebral palsy.

\section{DISCUSSION}

In the present study on shock in children, the commonest age group affected was the 1-5 years age group which accounted for $50 \%$ of the 70 children studied.

$60 \%$ of our children presented in compensated stage of shock. This is comparable to that found in other studies. ${ }^{3}$

The commonest type of shock found in our study was septic shock. (68.5\%) followed by hypovolemic (21.5\%). In a study by Singh et al, ${ }^{3}$ hypovolemic shock was the leading cause, accounting for $45 \%$ of cases followed by septic shock in $34 \%$. However, in a study by Vasundhara et al, ${ }^{4}$ septic shock was seen in $69 \%$ of case s of shock. Comparable results were seen in other studies. ${ }^{7,8}$ The incidence of hypovolemic shock, appears to be decreasing probably due to the effective management and prevention of acute diarrheal disease.

There were 48 patients with septic shock in the study. Pneumonia (54\%) was the commonest infection seen in these patients, other infections seen were dengue (29\%), meningitis, and urinary tract infection. In a study by Karada et al, pneumonia was the commonest cause of septic shock (51\%), followed by cellulitis/ abscess in $30.2 \%$. Blood culture was positive in $20 \%$ of patients with septic shock. Klebsiella and Staphylococcus aureus were the predominant organisms isolated. In a study by Kurade et al,8 Staphylococcus aureus was the most common organism isolated. In other studies 9,10 gram-negative organisms accounted for $55 \%$ of cases of septic shock.

$28.5 \%$ of patients with shock expired. The mortality was highest in cardiogenic shock (60\%). 35.4\% of patients with septic shock died. $75 \%$ of these patients with septic shock who died presented in a late decompensated stage. In a study by Singh et al, 3 the mortality was $26 \%$ in shock. Mortality of $47 \%$ was reported in septic shock. A study by Kaur G et al,11 reported a mortality rate of $42 \%$ in septic shock. Other Indian studies have also reported a high mortality rate in septic shock. ${ }^{12,13}$

\section{CONCLUSION}

Shock, one of the most common paediatric emergencies affects children predominantly in the age group of 1 month to 5 years. Septic shock is the commonest type of shock, followed by hypovolemic shock. Septic shock, especially when it presents at a late stage, is associated with very high mortality.

\section{REFERENCES}

[1] Shock ZB. Ischemic and reperfusion injury. In: Nicols DG, edr. Roger's Text book of Pediatric Intensive Care. $5^{\text {th }}$ edn. Philadelphia: Wolters Kluwer 2016: p. 253.

[2] Tumer DA, Cheifetz IM. Shock. In: Kleigman LB, Stanton BMD, St. Geme JW, eds. Nelson Text Book of Pediatrics. 20th edn. Philadelphia: Elsevier 2016: p. 516-27.

[3] Singh D, Chopra A, Pooni PA, et al. A clinical profile of shock in children in Punjab, India. Indian Pediatr 2006;43(7):619-23.

[4] Vasundhara A, Sahoo MR, Chowdary SS. Assessment of clinical parameters and immediate outcome of children with shock in a tertiary care hospital ASRAM, Eluru, Andhra Pradesh, India. Indian Journal of Contemporary Pediatrics 2017;4(2):586-90.

[5] Post-resucitation management. In: Chamedies L, Samson RA, Schexnayder SM, eds. Pediatric advanced life support: provider manual. American Heart Association 2016: p. 171.

[6] WHO. Guideline: Updates on Pediatrics emergency, triage, assessment and treatment: care of critically ill children. WHO, 2016: p. 5. 
[7] Ravikanth M, Singh HKG, Shrinivasreddy B. Clinical study of shock in children with special reference to prognostic determinant at teaching hospital. Bangalore Med Innovat 2015;4(1):1-7.

[8] Kurade A, Dhanwade S. Clinical profile and outcome of septic shock in children admitted to a tertiary care hospital. Pediatr Rev Int J Pediatr Res 2016;3(4):22530.

[9] Chanag P, Has HY, Chang MH, et al. Shock in the pediatric emergency service: five years' experience. Acta Pediatrics Taiwanica 1999;40(1):9-12.

[10] Dahmash NS, Chowdhury NH, Fayed DF. Septic shock in critically ill patients: aetiology, management and outcome. J Infect 1993;26(2):159-70.
[11] Kour G, Vinayak N, Mittal K, et al. Clinical outcome and predictors of mortality in children with sepsis, severe sepsis and septic shock from Rohtak, Haryana: a prospective observational study. Indian J Crit Care Med 2014;18(7):437-41.

[12] Valoor HT, Singhi S, Jayasree M. Low-dose hydrocortisone in pediatric septic shock: an exploratory study in a third world setting. Pediatr Crit Care Med 2009;10(1):121-5.

[13] Sarthi M, Lodha R, Vivekanandhan S, et al. Adrenal status in children with septic shock using low-dose stimulation test. Pediatr Crit Care Med 2007;8(1):23-8. 